\title{
A syndrome of hypogonadism, alopecia, diabetes mellitus, mental retardation, deafness, and ECG abnormalities
}

\author{
NICHOLAS J Y WOODHOUSE* AND NADIA A SAKATI $\dagger$ \\ From the Departments of Medicine* and Paediatrics $\dagger$, King Faisal Specialist Hospital, Saudi Arabia.
}

SUMMARY A distinct and previously undescribed syndrome has been observed in six Saudi Arabian $\bar{\Xi}^{\circ}$ patients from two highly inbred families. The parents were normal, indicating an autosomal recessive $\tilde{O}$ pattern of inheritance. All the patients have a distinctive facial appearance, hypogonadism, sparse $\dot{\omega}$ or absent hair, diabetes mellitus, mental retardation, mild deafness, and variable $S-T$ and $T$ wave $\frac{N}{\sigma}$ abnormalities on the electrocardiograph.

We have investigated six Saudi Arabian patients with hypogonadism, sparse hair, diabetes mellitus, mental retardation, deafness, and ECG abnormalities. A syndrome of deafness, alopecia, and hypogonadism was described by Crandall et al, ${ }^{1}$ but those patients were not diabetic and they had the hair abnormalities characteristic of pili torti, ${ }^{23}$ which our patients did not. The findings in our six patients indicate a previously undescribed hereditary syndrome affecting six apparently unrelated systems.

\section{Case reports}

The patients were all seen at the King Faisal Specialist Hospital between September 1981 and April 1982. There were two females and two males in family $A$ (cases 1 to 4 ) and one female and one male in family $B$ (cases 5 and 6 ). The family pedigrees are shown in figs 1 and 2. Initially one female from each family was referred to the joint adult/paediatric endocrine clinic for evaluation of primary amenorrhoea and failure of sexual development. The remaining patients in family $A$ were diagnosed during routine screening of potentially affected members, whereas the male patient in family B was diagnosed during admission to hospital for a seizure disorder secondary to a subdural empyaema. A similarly affected brother died of unknown causes aged approximately 45 years.

The patients had a distinctive facial appearance (fig $3 a, b, c)$. All were of normal height but with eunuchoid proportions. There was complete absence of breast tissue and sexual hair in all the women, whereas moderate growth of pubic hair and genital development was apparent in the older men.

There was variable loss of eyebrow and scalp hair, $\vec{\oplus}$ the latter being short, sparse, and fine and without microscopical evidence of pili torti. Hair loss was most severe in the older patients. There were no abnormalities of teeth, nails, or motor system.

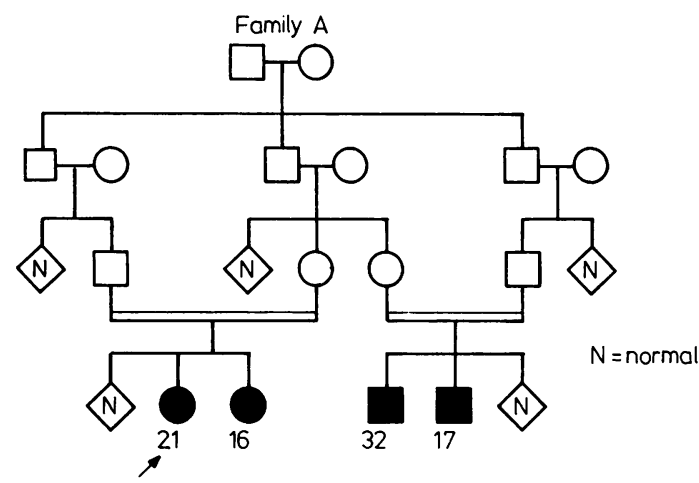

FIG 1 Pedigree of family $A$, a highly inbred family showing autosomal recessive inheritance.

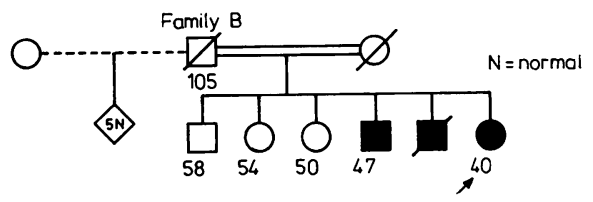

FIG 2 Pedigree of family $B$. The parents are first cousins with two sons and one daughter affected illustrating autosomal recessive inheritance. 
(a)

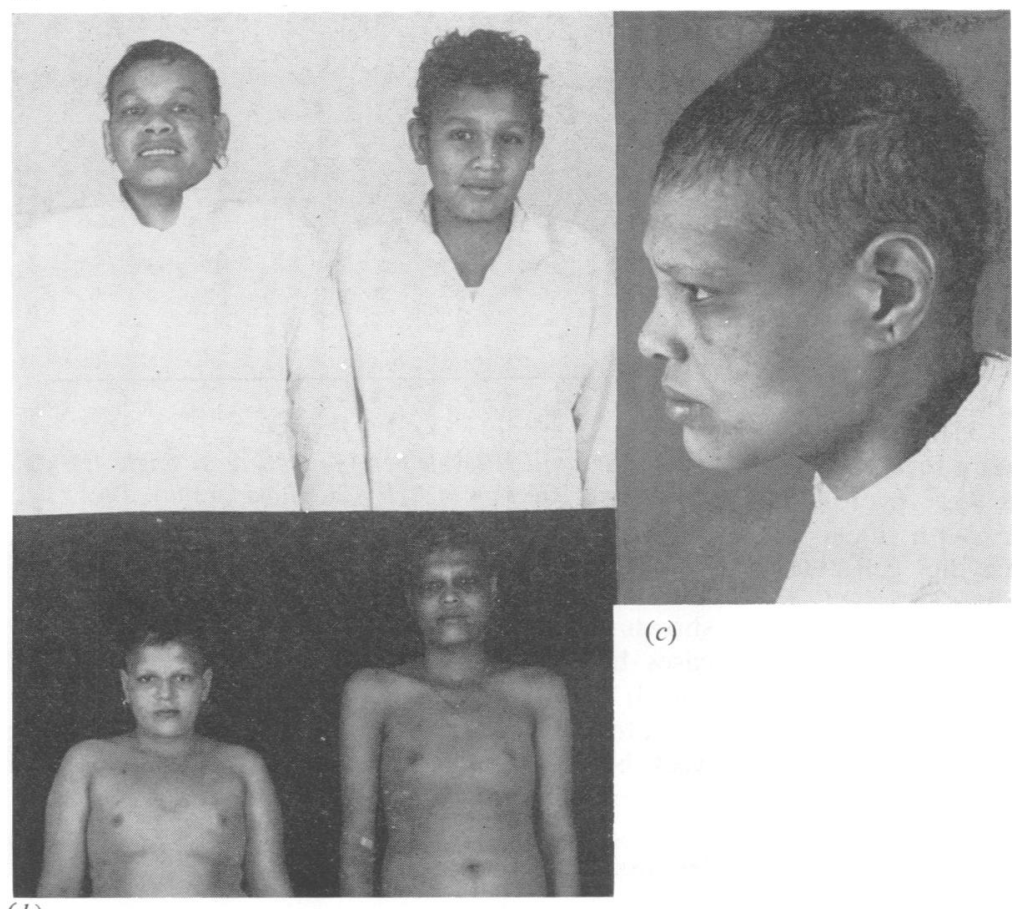

FIG 3 (a) Cases 3 and 4 from family $A$ showing lack of facial hair and more severe scalp hair loss in the older brother. (b) Cases 1 and 2 from family $A$. Complete sexual infantalism was present in both patients. (c) Case 1 showing marked thinning of scalp and eyebrow hair and scanty eyebrows.

(b)

Clinical assessment of intellectual impairment ranged from mild (cases 2 and 4) to moderate (cases 1, 5, and 6) and severe (case 3). There was no evidence of diabetic nephropathy or retinopathy in any patient, but the ankle jerks were absent in case 5 .

\section{Methods}

The CBC and SMAC 20 profiles were carried out using a Coulter S Counter and Technicon SMAC 20 Autoanalyzer. The radioimmunoassays were performed by standard procedures using commercially available kits from InterScience Institute, Los
Angeles, California (LH, FSH, testosterone, oestradiol, and prolactin) and New England Nuclear, Massachusetts (cortisol).

\section{LABORATORY DATA}

The relevant endocrine studies are shown in the table. Routine CBC, urine analysis, and SMAC 20 profiles were normal in all patients, except for hyperglycaemia and minimal raising of $\mathrm{LDH}$ in cases 2, 4, and 5. A $75 \mathrm{~g}$ glucose tolerance test was performed in patients 2 and 4 and the 2-hour blood sugar value was greater than $0.2 \mathrm{~g} / \mathrm{l}$ in both.

TABLE Results of endocrine studies.

\begin{tabular}{|c|c|c|c|c|c|c|c|c|c|c|c|}
\hline Case & $\operatorname{Sex}$ & Age & Testosterone & Oestradiol & $L H$ & $F S H$ & Prolactin & Thyroxine & Cortisol & $F B S$ & Insulin \\
\hline 1 & $\mathbf{F}$ & 21 & - & $>10$ & $11 \cdot 8$ & 18 & $5 \cdot 0$ & $5 \cdot 3$ & 116 & 287 & 21 \\
\hline 2 & $F$ & 16 & - & $>10$ & $34 \cdot 0$ & $38 \cdot 2$ & $13 \cdot 9$ & $5 \cdot 6$ & 139 & 135 & 50 \\
\hline 3 & $\mathbf{M}$ & 22 & 340 & - & $8 \cdot 0$ & $4 \cdot 5$ & 54 & $5 \cdot 5$ & 一 & 334 & $13 \cdot 9$ \\
\hline 4 & $\mathbf{M}$ & 17 & $34 \cdot 8$ & - & $5 \cdot 3$ & $4 \cdot 3$ & 71 & $7 \cdot 4$ & - & 119 & 28 \\
\hline 5 & $\mathbf{F}$ & 40 & - & $>10$ & $22 \cdot 6$ & $33 \cdot 5$ & $6 \cdot 4$ & $8 \cdot 6$ & 151 & 241 & $73 \cdot 5$ \\
\hline 6 & $\mathbf{M}$ & 47 & 258 & 一 & $6 \cdot 9$ & $13 \cdot 4$ & $1 \cdot 0$ & - & - & 250 & $11 \cdot 5$ \\
\hline \multicolumn{3}{|c|}{$\begin{array}{l}\text { Normal } \\
\text { ranges }\end{array}$} & $\begin{array}{l}450-1000 \\
\mathrm{ng} / \mathrm{dl}\end{array}$ & $\begin{array}{l}62-128 \\
\mathrm{pg} / \mathrm{ml}\end{array}$ & $\begin{array}{l}5-20 \\
\mathrm{mIU} / \mathrm{ml}\end{array}$ & $\begin{array}{l}\text { 4-19 } \\
\mathrm{mIU} / \mathrm{ml}\end{array}$ & $\begin{array}{l}\mathrm{m} 0-12 \\
\mathrm{f} 0-21 \\
\mathrm{ng} / \mathrm{ml}\end{array}$ & $\begin{array}{l}5 \cdot 1-12 \cdot 3 \\
\mu \mathrm{g} / \mathrm{dl}\end{array}$ & $\begin{array}{c}90-250 \\
\mathrm{ng} / \mathrm{ml}\end{array}$ & $\begin{array}{l}60-110 \\
\mathrm{mg} / \mathrm{dl}\end{array}$ & $\begin{array}{l}6 \cdot 5-34 \\
\mu \mathrm{U} / \mathrm{ml}\end{array}$ \\
\hline \multicolumn{3}{|c|}{ SI units } & $\begin{array}{l}15 \cdot 6-35 \cdot 0 \\
\mathrm{nmol} / \mathrm{l}\end{array}$ & $\begin{array}{l}228-470 \\
\mathrm{pmol} / \mathrm{l}\end{array}$ & & & $\begin{array}{l}\mathrm{m} \mathrm{0-228} \\
\mathrm{f} \mathrm{0-399} \\
\mathrm{n} \mathrm{mol} / \mathrm{l}\end{array}$ & $\begin{array}{l}60-158 \\
\mathrm{nmol} / 1\end{array}$ & $\begin{array}{l}248-690 \\
\mathrm{nmol} / 1\end{array}$ & $\begin{array}{l}3 \cdot 33-6 \cdot 11 \\
\mathrm{nmol} / 1\end{array}$ & \\
\hline
\end{tabular}


ELECTROCARDIOGRAPH

The ECG was abnormal in cases $1,2,3$, and 5 and within normal limits in case 4 . There was $\mathbf{S}-\mathbf{T}$ segment depression in cases 1 and 5 and flattening of the $T$ wave in all affected persons.

\section{RADIOLOGY}

Radiographs of the chest and spine were within normal limits. Computerised tomography of the brain was normal except for case 1 who had periand supraventricular hypodense areas of uncertain significance.

TESTICULAR HiSTOLOGY (CASE 3)

The tubules showed moderately severe hypospermatogenesis and Sertoli cells were prominent. There were some atrophic tubules with thickening of the basement membrane. Leydig cells were present but relatively few in number.

\section{AUDIOGRAMS}

Sensorineural deafness was demonstrated in the four patients tested and was mild in two, moderate in one, and moderately severe in one (mild 20 to $40 \mathrm{~dB}$, moderate 40 to $55 \mathrm{~dB}$, and moderately severe 55 to $70 \mathrm{~dB}$ ).

\section{FURTHER STUDIES (CASE 1)}

Laparotomy revealed a hypoplastic uterus, rudimentary fallopian tubes, and streak ovaries. Histology of the gonadal streak revealed a fibrous stroma with small calcified deposits but no oogonia. The dermis of the scalp was slightly atrophic with scant hair follicles and sebaceous glands, and the hair shafts were excessively keratinised. Neither pili torti nor immunoglobulin deposit was see on immunofluorescent staining. Coronary angiography and haemodynamic studies performed during catheterisation were all normal.

\section{Results}

All patients had hypogonadism with low oestradiol or testosterone levels. The LH and FSH levels were raised in cases 2 and 5 and normal in cases $1,3,4$, and 6. All patients were diabetic with inappropriately low serum insulin levels. There were no circulating antibodies directed against islet cells, ovary, testis, thyroid or adrenal glands and the karyotypes were normal. There was no evidence of thyroid or adrenal dysfunction (table). The prolactin levels in cases 3 and 4 were raised initially but subsequently returned to normal.

\section{RELEASING HORMONE STUDIES}

The LH response to a single intravenous bolus injection of $100 \mu \mathrm{g} \mathrm{LH}-\mathrm{RH}$ (Gonadorelin, Ayerst) is

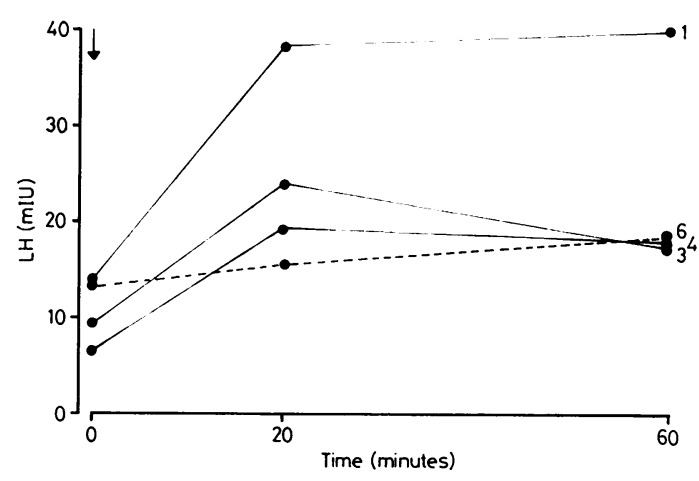

FIG 4 Serum LH levels before and after a single $100 \mu \mathrm{g}$ intravenous injection of $\mathrm{LH}-\mathrm{RH}$ (Gonadorelin). The injection is indicated by the arrow.

shown in fig 4. A rise in $\mathrm{LH}$ occurred in all four cases but was most marked in those (cases 1, 3, and 4) who had been pretreated with a twice daily subcutaneous injection of $100 \mu \mathrm{g}$ LH-RH for one week before the test. FSH levels were increased in two patients (results not shown).

\section{Discussion}

All the patients had inherited abnormalities apparently affecting six unrelated systems: hypogonadism, diabetes mellitus, alopecia, mental retardation, sensorineural deafness, and ECG abnormalities. The most striking feature was the failure, particularly in the women, of sexual maturation. None of them had anosmia, thereby ruling out Kallman's syndrome, ${ }^{4}$ a disorder characterised by hypothalamic hypogonadism and agenesis of the olfactory nerves. ${ }^{5}$ The mechanisms responsible for the hypogonadism were surprisingly nonuniform; two unrelated females had hypergonadotrophic ovarian failure, three males had hypogonadotrophic testicular failure that proved to be hypothalamic in nature, and the remaining female had both hypothalamic and ovarian failure. Diabetes mellitus, with inappropriately low serum insulin levels, was present in all the patients as well, but there was no evidence of an underlying autoimmune disorder to explain the endocrine abnormalities.

Hypogonadism, diabetes mellitus, mental retardation, and sometimes sensorineural deafness occur in three distinct autosomal recessive syndromes, ${ }^{6-8}$ but there are major clinical differences between them and the characteristics of the patients described here. Hypergonadotrophic hypogonadism occurs in Alström's syndrome ${ }^{7}$ and hypothalamic hypogonadism in the Laurence-Moon-Biedl syndrome, ${ }^{6}$ 
and obesity and retinitis pigmentosa occur in both disorders. Skeletal abnormalities predominate in the Sohval-Soffer syndrome ${ }^{8}$ and hypergonadotrophic hypogonadism is characteristic. Furthermore, alopecia and ECG abnormalities are not seen in these disorders. On the other hand patients with the Crandall syndrome (hypogonadism, alopecia, and sensorineural deafness) ${ }^{1}$ are not diabetic, have no ECG abnormalities, but do have pili torti.

The ECG abnormalities were marked in patients 1 and 5 but there was no evidence of coronary artery disease or cardiac dysfunction. Patients with dystrophia myotonica may have ECG abnormalities, hypogonadism, and diabetes mellitus but differ from our patients in having myotonia, a different and characteristic facial appearance, cataracts, frontal balding in the male, and an autosomal dominant pattern of inheritance. ${ }^{9}$

We cannot link the widespread nature of our patients' abnormalities biochemically, but from the family pedigrees it would appear that the abnormalities described are inherited as an autosomal recessive trait and, to the best of our knowledge, have not been reported previously.

We would like to thank many colleagues for their help in studying these patients: Dr Fawzy, Dr McDonald, Dr Akhtar, and Dr Godwin and his many able assistants in chemical pathology. Dr AlKawi kindly allowed us to publish details of one patient and we were fortunate that Professor D
Doniach was able to screen our patients' serum for antibodies directed against endocrine tissue.

\section{References}

1 Crandall BF, Samec L, Sparkes RS. A familial syndrome of deafness, alopecia and hypogonadism. J Pediarr $1973 ; 82: 461-5$.

2 Bjornstad R. Pili torti and sensory neural loss of hearing. Proceedings of the 17th Meeting of the Northern Dermatological Society (Copenhagen), May 27-29, 1965.

3 Robinson GC, Johnston MM. Pili torti and sensory neural hearing loss. J Pediatr 1967;70:621-3.

4 Kallman FJ, Schoenfeld WA, Barrera SE. The genetic aspect of primary eunuchoidism. Am J Ment Defic $1944 ; 48: 203-36$.

5 Males JL, Townsend JL, Schneider RA. Hypogonadotrophic hypogonadism with anosmia-Kallman's syndrome: a disorder of olfactory and hypothalamic function. Arch Intern Med 1973;131:501-7.

- Biedl A. Ein geschwisterpaar mit adiposa-genitalen dystrophie. Dtsch Med Wochenschr 1922;48:1630.

7 Alström CH, Hallgren B, Nilsson LB, Asander $\mathbf{H}$. Retinal degeneration combined with obesity, diabetes mellitus and neurogenous deafness: a specific syndrome distinct from the Laurence-Moon-Biedl syndrome. A clinical endocrinological and genetic examination based on a large pedigree. Acta Psychiatr Scand 1959;34: suppl 129.

8 Sohval AR, Soffer LJ. Congenital familial testicular deficiency. Am J Med 1953;14:328-48.

9 Ulloa-Aguirre A, Larrea F, Shkurovich M. Hypothalamic hypogonadism in myotonic dystrophy. Obstet Gynecol $1981 ; 57$ (suppl) :67-9.

Correspondence and requests for reprints to Dr N J Y Woodhouse, Department of Medicine, King Faisal Specialist Hospital, PO Box 3354, Riyadh 11471, Saudi Arabia. 